J. Lake Sci. (湖泊科学 ), 2006, 18( 1 ):69-72

http:// www. jlakes. org. E-mail: jlakes@ niglas. ac.cn

(c) 2006 by Journal of Lake Sciences

\title{
太湖春季浮游动物磷释放的初步研究"
}

\author{
潘宏凯 ${ }^{1,2,3}$, 杨桂军 ${ }^{4}$, 刘正文 ${ }^{1 * *}$
}

(1: 中国科学院南京地理与湖泊研究所, 南京 210008)

(2: 中国科学院研究生院, 北京 100039 )

( 3 : 上海立信会计学院, 上海 201620)

( 4 : 华中农业大学水产学院, 武汉 430070 )

摘 要: 浮游动物是湖泊生态系统的主要组成之一, 于 2004 年 3 月至 5 月间调查了太湖梅梁湾、五里湖浮游动物数量, 并 在实验室条件下分别测定了浮游动物正磷酸盐 $\left(\mathrm{PO}_{4}-\mathrm{P}\right)$ 的释放率. 结果表明, 研究期间梅梁湾的枝角类密度都高于五 里湖, 五里湖的轮虫数量高于梅梁湾, 两水域桡足类密度上的差异不明显; 梅梁湾和五里湖浮游动物 $\mathrm{PO}_{4}-\mathrm{P}$ 释放率的范 围分别为 $0.20-0.43 \mathrm{mg} /(\mathrm{g}(\mathrm{DW}) \cdot \mathrm{h})$ 和 $0.19-0.54 \mathrm{mg} /(\mathrm{g}(\mathrm{DW}) \cdot \mathrm{h})$. 因此浮游动物营养盐释放对湖泊生态系统 营养盐循环具有一定的作用.

关键词:太湖; 浮游动物; 磷释放

\section{Phosphorus Release by Zooplankton in Lake Taihu in Spring}

PAN Hongkai ${ }^{1,2,3}$, YANG Guijung ${ }^{4} \&$ LIU Zhengwen ${ }^{1}$

( 1: Institute of Geography and Limnology, Chinese Academy of Sciences, Nanjing 210008, P. R. China)

( 2: Graduate School of Chinese Academy of Sciences, Beijing 100039, P. R. China)

( 3: Shanghai Lixin University of Commerce, Shanghai 201620, P. R. China)

( 4: Fisheries College, Huazhong Agricultural University, Wuhan 430070, P. R. China)

Abstract: Zooplankton is one of the most important components in lake ecosystems. The zooplankton abundance and $\mathrm{PO}_{4}-\mathrm{P}$ released by zooplankton community in Meiliang Bay and Lake Wuli, Lake Taihu were studied from March to May in 2004. The results showed that the cladoceran density in Meiliang Bay was always higher than that in Lake Wuli. However, the abundance of rotifers was higher in Lake Wuli than Meiliang Bay; and the difference of copepods was not significant. $\mathrm{PO}_{4}-\mathrm{P}$ releasing rates ranged from 0.20 to $0.43 \mathrm{mgP} /(\mathrm{g}(\mathrm{DW}) \cdot \mathrm{h})$ in Meiliang Bay, and from 0.19 to $0.54 \mathrm{mg} /(\mathrm{g}(\mathrm{DW}) \cdot \mathrm{h})$ in Lake Wuli. Present study suggests that nutrient release by zooplankton can play an important role in nutrient regeneration in lake ecosystems.

Keywords: Lake Taihu; zooplankton; phosphorus release

浮游动物是湖泊生态系统的重要组成部分, 它既是细菌、浮游植物等初级生产者的牧食者,也是鱼类等 其它动物的重要食物, 其变化会影响到其它营养级和食物网结构的变化, 因此, 浮游动物也是经典生物操纵 ( biomanipulation) 的主要环节之一 ${ }^{[-5]}$; 另一方面,浮游动物对氮、磷等生源要素的排泄是初级生产者的主 要营养盐来源之一 ${ }^{[6-11]}$. 水体中浮游动物释放的氮、磷的量有时甚至会超过浮游植物对氮、磷的需 求量 $[12,13]$.

太湖是我国五大淡水湖之一, 从上世纪七十年代末、八十年代初开始富营养化日趋严重. 五里湖是位

* 国家自然科学基金项目 (40371103)、中国科学院知识创新工程领域前沿项目( CXNIGLAS - 402-03) 和中国科学 院知识创新工程重大项目联合资助 (KZCX1 - SW - 12). $2005-03-25$ 收稿; 2005-06-24 收修改稿. 潘宏凯, 男,1981 生,硕士研究生.

** 通信作者;E-mail:zliu@ niglas.cn.on. 
于太湖东北部的湖湾, 几乎成为无锡市的一个城市湖泊, 受到的污染较严重, 是太湖中营养水平最高的水 域;梅梁湾是太湖北部一个较大的湖湾, 富营养化水平仅次于五里湖. 有关太湖浮游动物种类和生物量方 面已有一些研究 ${ }^{[14-16]}$, 而本文对太湖梅梁湾和五里湖春季浮游动物的磷释放进行了初步研究, 以探讨浮游 动物的功能, 尤其是对太湖营养盐循环的贡献.

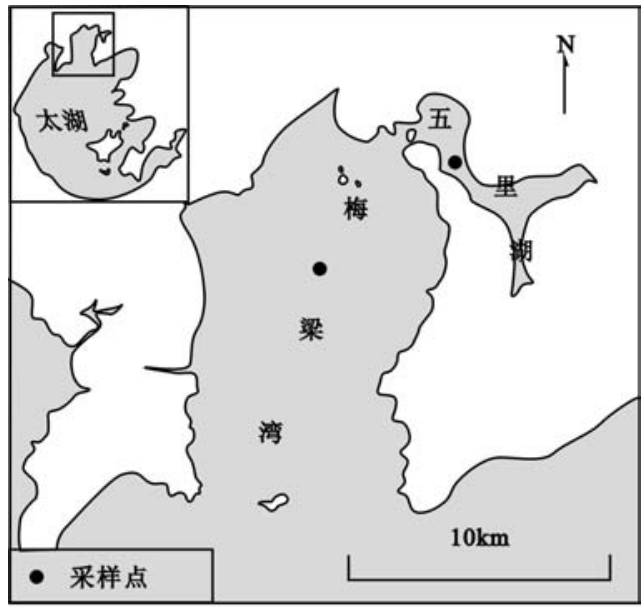

图 1 采样点分布图

Fig. 1 Sampling Stations

\section{1 材料与方法}

在太湖梅梁湾和五里湖分别选取一点( 图 1 ), 采集水 样 $20 \mathrm{~L}$,采样从 2004 年 3 月 9 日开始, 5 月 22 日结束, 每 月采样二到三次. 水样带到实验室后先取 $5 \mathrm{~L}$ 水样, 用 63 $\mu \mathrm{m}$ 的篮网浓缩浮游动物, 然后固定于 $5 \%$ 的福尔马林溶 液, 在显微镜下分类计数、测量体长, 根据浮游动物体长、 生物量关系测算湖泊浮游动物生物量 ${ }^{[17]}$; 其中轮虫定量 计数前将沉淀样品充分摇匀, 然后吸取 $1 \mathrm{ml}$ 注人 $1 \mathrm{ml}$ 计 数框内, 在 $10 \times 10$ 倍视野下进行全片计数, 每个样本重 复计数两次, 取其平均值. 其他水样用 $63 \mu \mathrm{m}$ 的笁网浓缩 浮游动物, 获取的浮游动物用蒸馏水冲洗二到三次, 洗去 浮游动物身体表面的营养盐. 冲洗之后将浮游动物放人 事先装好 $500 \mathrm{ml}$ 蒸馏水的烧杯中, 在加人浮游动物后的 0 $\mathrm{h} 、 1 \mathrm{~h}$ 和 $2 \mathrm{~h}$ 后用注射器( 注射器口用 $45 \mu \mathrm{m}$ 的网绢包住 防止吸人浮游动物) 抽取 $100 \mathrm{ml}$ 水样, 测定正磷酸盐. 设 三个重复,一个空白对照.

实验结束后剩下水样用事先烘干、称重的玻璃纤维滤纸( Whatman GF/C) 过滤, 然后再烘干、称重, 以获 得实验浮游动物的干重. 最后, 根据培养期间正磷酸盐浓度的变化和实验浮游动物的生物量 (干重 DW )计 算出每小时单位重量浮游动物释放的正磷酸盐 $\left(\mathrm{mg}\left(\mathrm{PO}_{4}-\mathrm{P}\right) /(\mathrm{g}(\mathrm{DW}) \cdot \mathrm{h})\right.$, 即释放速率.

\section{2 结果与讨论}

太湖梅梁湾和五里湖在研究期间浮游动物的种类组成存在较大差异 (表 1 ). 梅梁湾的枝角类( 主要是 象鼻溞、透明溞、长刺溞、蚤状溞、裸腹溞等)数量变化在 20-212 ind. / L 之间,都高于五里湖. 桡足类( 包括 无节幼体) (主要种类包括许水蚤、华哲水蚤、中剑水蚤、近邻剑水蚤等)的数量两个采样点的变化都较大, 差异不明显. 轮虫的密度则在五里湖一直高于梅梁湾, 前者轮虫数量在 $62-1232 \mathrm{ind}$. $/ \mathrm{L}$ 之间, 后者轮虫 数量变化在 $2-98$ ind. / L 之间. 这种差别可能与很多因子相关:五里湖的营养状态高于梅梁湾, 很多研究 表明随着富营养化的加剧, 浮游动物会出现小型化, 小的个体和种类在营养丰富的环境里往往能获得竞争 优势 ${ }^{[18]}$; 另外五里湖鱼类密度较高, 由于鱼类的选择性捕食, 使得大型浮游动物死亡率大大提高, 其密度 较低.

表 1 研究期间太湖梅梁湾、五里湖浮游动物密度变化 ( ind. / L )

Tab. 1 Zooplankton abundance( ind. /L ) in Meiliang Bay and Lake Wuli during the study period

\begin{tabular}{|c|c|c|c|c|c|c|c|c|c|c|c|c|c|c|}
\hline 月.日 & 3. & 9 & 3. & 18 & 3. & 26 & 4. & 6 & 4. & 15 & 4. & 22 & & 16 \\
\hline 采样点 & 五里湖 & 梅梁湾 & 五里湖 & 梅梁湾 & 五里湖 & 梅梁湾 & 五里湖 & 梅梁湾 & 五里湖 & 梅梁湾 & 五里湖 & 梅梁湾 & 五里湖 & 梅梁湾 \\
\hline 轮虫 & 453.4 & 97.6 & 389.6 & 6.2 & 1231.6 & 50.2 & 104.8 & 25.4 & 102.4 & 7.8 & 62.5 & 2.2 & 925 & 97.8 \\
\hline 枝角类 & 5.4 & 54.2 & 17.2 & 28.8 & 0 & 22.2 & 16 & 8.8 & 3.4 & 56.2 & 6.4 & 143.4 & 63.6 & 211.2 \\
\hline 桡足类 & 3.2 & 35.2 & 12 & 9.4 & 19.8 & 69 & 20.4 & 16.6 & 61 & 43.2 & 27.8 & 22.4 & 39.4 & 17.4 \\
\hline $\begin{array}{l}\text { 无节 } \\
\text { 幼体 }\end{array}$ & 5 & 48.4 & 0 & 50.6 & 4.8 & 69.2 & 63.2 & 25.6 & 36.4 & 51.2 & 57.4 & 5.4 & 57.8 & 35 \\
\hline 总计 & 467 & 235.4 & 419 & 95 & 1256.2 & 210.6 & 204.4 & 76.4 & 203.2 & 158.4 & 154.2 & 173.4 & 1085.8 & 361.4 \\
\hline
\end{tabular}


从图 2 可以看出, 不管是梅梁湾还是五里湖, 浮游动物在第 $1 \mathrm{~h}$ 对 $\mathrm{PO}_{4}-\mathrm{P}$ 的释放率一般都高于第 2 小 时. 这与其他作者的结果相似. 如桡足类的氨氮排泄率每小时递减 8.4\% ${ }^{[13]}$, 而 Pinto-Coelho ${ }^{[19]}$ 也发现, 浮游动物 $\mathrm{PO}_{4}-\mathrm{P}$ 释放率随培养时间的增加而降低. 这主要是因为该实验是在饥饿状态下进行的,浮游动 物在无食物的情况下其营养盐的释放速率逐渐下降. 因此在第 1 小时测得的浮游动物营养盐释放速率应 该更接近浮游动物的原位释放速率.

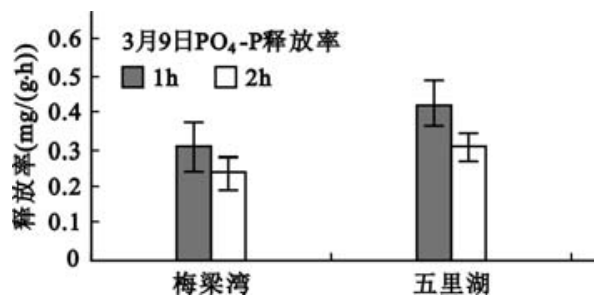

图 22004 年 3 月 9 日释放实验第 $1 \mathrm{~h}$ 和第 $2 \mathrm{~h}$ 测得的浮游动物 $\mathrm{PO}_{4}-\mathrm{P}$ 释放率

Fig. $2 \mathrm{PO}_{4}-\mathrm{P}$ releasing rate by zooplankton during the 1st and 2nd hour of the experiments on March 9, 2004

从本实验第 $1 \mathrm{~h}$ 测定的 $\mathrm{PO}_{4}-\mathrm{P}$ 释放率看, 梅梁湾浮游动物释放率在 $0.20-0.43 \mathrm{mg} /(\mathrm{g}(\mathrm{DW}) \cdot \mathrm{h})$ 之 间, 而在研究期间不同采样时间释放率变化不大. 五里湖浮游动物的 $\mathrm{PO}_{4}-\mathrm{P}$ 释放率在 $0.19-0.54 \mathrm{mg} /(\mathrm{g}$ $(\mathrm{DW}) \cdot \mathrm{h})$ 之间. 与其它研究相比, 本研究所获得的浮游动物 $\mathrm{PO}_{4}-\mathrm{P}$ 释放率虽然偏低, 但仍在范围之内. 如 Pinto-Coelho ${ }^{[19]}$ 发现巴西一水库浮游动物 $\mathrm{PO}_{4}-\mathrm{P}$ 释放率在 $0.49-1.05 \mathrm{mg} /(\mathrm{g}(\mathrm{DW}) \cdot \mathrm{h})$ 之间, Leh$\mathrm{man}^{[8]}$ 报道溞属一种的正磷盐释放率为 $0.58-0.83 \mathrm{mg} /(\mathrm{g}(\mathrm{DW}) \cdot \mathrm{h})$. 两采样点浮游动物磷释放率虽然 数值波动较大, 但总体来讲五里湖浮游动物营养盐释放率高于梅梁湾. 特别是在 3 月底 4 月初五里湖轮虫 密度较高时, 两处浮游动物释放率差异较为突出. 不同大小种类或同一种类不同个体浮游动物营养盐释放 率不同已有报道, Pérz-Martínez \& Gulati ${ }^{[20]}$ 发现僧帽溞的幼体 P 释放率在 $1.93-2.37 \mathrm{mg} /(\mathrm{g}(\mathrm{DW}) \cdot \mathrm{h})$, 显 著高于其成体的释放率 $1.00-1.24 \mathrm{mg} /(\mathrm{g}(\mathrm{DW}) \cdot \mathrm{h})$; 阮景荣 ${ }^{[6]}$ 在研究大型掻的磷释放时发现释放率与 其个体大小成负相关关系. 五里湖轮虫等小型浮游动物较丰富, 可能是导致其正磷酸盐释放率高的原因之 一. 影响浮游动物营养盐释放率还有其他因素, 如细菌和藻类对营养盐的吸收等, 虽然实验中尽力避免藻 类的混人,但细菌对磷的吸收可能会导致营养盐释放速率估算偏低.

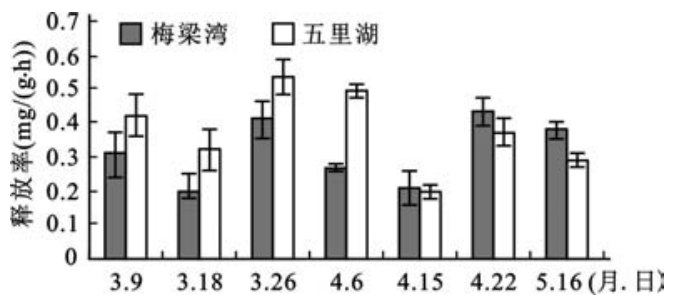

图 3 太湖梅梁湾、五里湖 2004 年春季浮游动物 $\mathrm{PO}_{4}-\mathrm{P}$ 释放率

Fig. $3 \mathrm{PO}_{4}-\mathrm{P}$ releasing rates by zooplankton in Meiliang Bay and Lake Wuli, Lake Taihu in the spring of 2004

\section{3 结语}

太湖梅梁湾、五里湖春季浮游动物的密度波动较大, 枝角类的数量在梅梁湾高于五里湖, 五里湖的轮虫 密度高于梅梁湾, 但两水域的桡足类在数量上的差异不大. 梅梁湾、五里湖浮游动物的 $\mathrm{PO}_{4}-\mathrm{P}$ 释放率分别 为 $0.20-0.43 \mathrm{mg} /(\mathrm{g}(\mathrm{DW}) \cdot \mathrm{h})$ 和 $0.19-0.54 \mathrm{mg} /(\mathrm{g}(\mathrm{DW}) \cdot \mathrm{h})$, 浮游动物的营养盐释放可能对湖泊生 态系统营养盐循环有较大的影响. 


\section{4 参考文献}

[1] Carpenter S R and others. Regulation of lake primary productivity by food web structure. Ecology, 1987, 68: $1868-1876$.

[ 2 ] Crowder L R and others. Food web interactions in lakes. In: Carpenter SR ed. Complex interactions in lake communities. Springer, 1988:141 - 160 .

[3] Vanni M J. Freshwater zooplankton community structure: Introduction of large invertebrate predators and large herbivores to a small speciescommunity. Can J Fish Aquat Sci, 1988, 45: 1758 - 1770.

[ 4 ] Gulati R D, Lammens E H R, Meijer M and van Donk ed. E. Biomanipulation: tool for water management. First international conference, 8 - 11 August 1989, Amsterdam, The Netherlands. Hydrobiologia, 1990, 200/201: $1-128$.

[ 5 ] Reynolds C S. The ecological basis for the successful biomanipulation of aquatic communities. Arch Hydrobi$o l, 1994,130: 1-33$.

[6] 阮景荣. 微型生态系统中浮游动物正磷酸盐排泄率的的估算. 水生生物学报, 1999, 23( 3 ): 204 $-209$.

[7] 李超伦等. 南极普里兹湾边缘冰区微型浮游动物的摄食及其氮的排泄. 海洋与湖沼, 2000, 31 ( 6 ): $657-663$.

[ 8 ] Lehman J T. Release and cycling of nutrients between planktonic algae and herbivores. Limnol Oceanogr, $1980,25: 620-632$.

[ 9 ] Elser J J, Elser M M, MacKay N A and Carpenter S R. Zooplankton mediated trasitions between N-and Plimited algal growth. Limnol Oceangr, $1988,36: 64-90$.

[ 10 ] Sterner R W, Elser J J, Hessen D O. Stoichiometric relationshiops among producers and consumers in food webs. Biogeochemistry, $1992,17: 49-67$.

[ 11 ] Sterner R W, Hessen D O. Algal nutrient limitation and the nutrition of aquatic herbivores. Ann Rev Ecol Syst, 1994, $25: 1-29$.

[ 12 ] Peters R H, Rigler F H. Phosphorus release by Daphnia. Limnol Oceanogr, 1973, 18: 270 - 279.

[ 13 ] Bümstedt U. Seasonal excretion rates of macrozooplankton from the Swedish west coast. Limnol Oceanogr, $1985,30(3): 607-617$.

[ 14 ] 白国栋. 五里湖 1951 年湖泊学调查—4:浮游动物. 水生生物学集刊, 1962, 2( 1):93-100.

[ 15 ] Chen W, Nauwerck A. A note on composition and feeling of the crustacean zooplankton of Lake Taihu, Jiangsu Province, China. Limnologica, 1996, 26( 3 ): 275 - 279.

[16] 陈伟民,秦伯强. 太湖梅梁湾冬末春初浮游动物时空变化及其环境意义. 湖泊科学, 1998, 10(4): 10 -17 .

[ 17 ] 章宗涉, 黄祥飞. 淡水浮游动物研究方法. 北京: 科学出版社,1991.

[ 18 ]Hall D J, Threlkeld S T, Burn C W \& Crowley P H. The size-efficiency hypothesis and the size structure of zooplankton communities. Ann Rev Ecol Syst, 1976, 7: 177 - 208.

[19] Pinto-Coelho R M, Greco M K B. The contribution of water hyacinth and zooplankton to the internal cycling of phosphorus in the eutrophic Pampulha Reservoir, Brazil. Hydrobiologia, 1999, 411: 115 - 127.

[ 20 ] Pérz-Martínez C, Gulati R D. Species-specific N and P release rates in Daphnia. Hydrobiologia, 1999, 391 : $147-155$. 